\title{
Will SCIENCE be stronger than POLITICS?
}

Our profession was based on the research, the enthusiasm, and the thoughtful insights of a great number of our colleagues. FAUCHARD, ANGLE, and RoBIN were a few of the pioneers, who, in consecrating their lives to their passion for orthodontics have inspired us with the clarity of their analyses, by the rigor of their research, and by the concept of "clinical quality" that they held up for us to emulate. RICKETTS, ZACHRISSON, and KOKICH were among the many talented successors to these visionaries.

On the Political front. Some of the public and private institutions responsible for paying providers of health services have leveled attacks against our profession, especially orthodontics, in order to contain expenses. These assaults are of two kinds, first trying to control costs by limiting certain procedures such as prostheses made by general dentists and yearly fees charged by orthodontists and, second, by exerting pressure on practitioners with controls that have nothing to do with quality, such as restrictions on some imported products and limitations of the services auxiliaries are allowed to perform.

On the Scientific front. We must remain devoted to the nobility of our profession by undertaking research projects and by writing articles disseminating our findings as well as by conducting and attending professional meetings. In that spirit, in 2010 Hugo De CLERCK made one of the most enthusiastically received contributions to our field by demonstrating the orthopedic effects of inter-maxillary forces continuously applied by means of screwed-in anchorage plates. He had previously published in this journal the results of intra-maxillary traction exerted from the fixed anchorage of bone screws or plates but his latest work promises the exciting and even more important possibility of remodeling skeletal structures with orthopedic forces.

On the future of our profession. The professional societies to which we belong will surely join forces with each other and with the faculties of university orthodontic department in order to insure delivery of constantly improving orthodontic and dento-facial orthopedic care in harmony with our humanist conception of our profession.

That is why the vision of Science must always be stronger than the force of Politics.

O. MAUCHAMP 